NBS

echnical Mote

$\eta_{0.118}$

Boulder Laboratories

\title{
A NOTE ON THE PROPAGATION \\ OF CERTAIN LF PULSES UTILIZED \\ IN A RADIO NAVIGATION SYSTEM
}

\author{
BY \\ J. R. JOHLER
}

U. S. DEPARTMENT OF COMMERCE

NATIONAL BUREAU OF STANDARDS 


\section{THE NATIONAL BUREAU OF STANDARDS}

\section{Functions and Activities}

The functions of the National Bureau of Standards are set forth in the Act of Congress, March 3, 1901, as amended by Congress in Public Law 619, 1950. These include the development and maintenance of the national standards of measurement and the provision of means and methods for making measurements consistent with these standards; the determination of physical constants and properties of materials; the development of methods and instruments for testing materials, devices, and structures; advisory services to government agencies on scientific and technical problems; invention and development of devices to serve special needs of the Government; and the development of standard practices, codes, and specifications. The work includes basic and applied research, development, engineering, instrumentation, testing, evaluation, calibration services, and various consultation and information services. Research projects are also performed for other government agencies when the work relates to and supplements the basic program of the Bureau or when the Bureau's unique competence is required. The scope of activities is suggested by the listing of divisions and sections on the inside of the back cover.

\section{Publications}

The results of the Bureau's research are published either in the Bureau's own series of publications or in the journals of professional and scientific societies. The Bureau itself publishes three periodicals available from the Government Printing Office: The Journal of Research, published in four separate sections, presents complete scientific and technical papers; the Technical News Bulletin presents summary and preliminary reports on work in progress; and Basic Radio Propagation Predictions provides data for determining the best frequencies to use for radio communications throughout the world. There are also five series of nonperiodical publications: Monographs, Applied Mathematics Series, Handbooks, Miscellaneous Publications, and Technical Notes.

A complete listing of the Bureau's publications can be found in National Bureau of Standards Circular 460, Publications of the National Bureau of Standards, 1901 to June 1947 (\$1.25), and the Supplement to National Bureau of Standards Circular 460, July 1947 to June 1957 (\$1.50), and Miscellaneous Publication 240, July 1957 to June 1960 (Includes Titles of Papers Published in Outside Journals 1950 to 1959) (\$2.25); available from the Superintendent of Documents, Government Printing Office, Washington 25, D. C. 


\section{NATIONAL BUREAU OF STANDARDS Eechnical Mote}

No. 118

\section{A NOTE ON THE PROPAGATION OF CERTAIN LF PULSES UTILIZED IN A RADIO NAVIGATION SYSTEM}

by

J. R. Johler

October 27,1961

NBS Technical Notes are designed to supplement the Bureau's regular publications program. They provide a means for making available scientific data that are of transient or limited interest. Technical Notes may be listed or referred to in the open literature. They are for sale by the Office of Technical Services, U. S. Depart-. ment of Commerce, Washington 25, D. C.

\section{DISTRIBUTED BY \\ UNITED STATES DEPARTMENT OF COMMERCE OFFICE OF TECHNICAL SERVICES \\ WASHINGTON 25, D. C.}

Price $\$ .75$ 

A NOTE ON THE PROPAGATION OF CERTAIN LF PULSES UTILIZED IN A RADIO NAVIGATION SYSTEM

by

J. R. Johler

\section{$\underline{\text { ABSTRACT }}$}

Low frequency pulses utilized in a radio navigation system can be synthesized and analyzed by a specialization of the general theory of pulse propagation. The analysis technique required to accomplish such a research is detailed, and the introduction of receiver and detector circuits into such an analysis is described. The time-difference dispersion correction, or the "discrepancy correction", for operation of a radio navigation pulse system on either the groundwave time mode or the ionospheric time modes of propagation is defined. 



\section{A NOTE ON THE PROPAGATION OF CERTAIN LF PULSES UTILIZED IN A RADIO NAVIGATION SYSTEM}

by

\section{J. R. Johler}

The interest in recent years in low frequencies (LF) has been inspired by the development of the Loran-C (Cytac) [Frantz, Dean, and Frank, 1957] and other [Schneider, 1955] [Ross, 1959] radio navigation and/or timing systems. The high reliability and predictability requirements of such systems leads the researcher and system designer quite naturally to low frequencies.

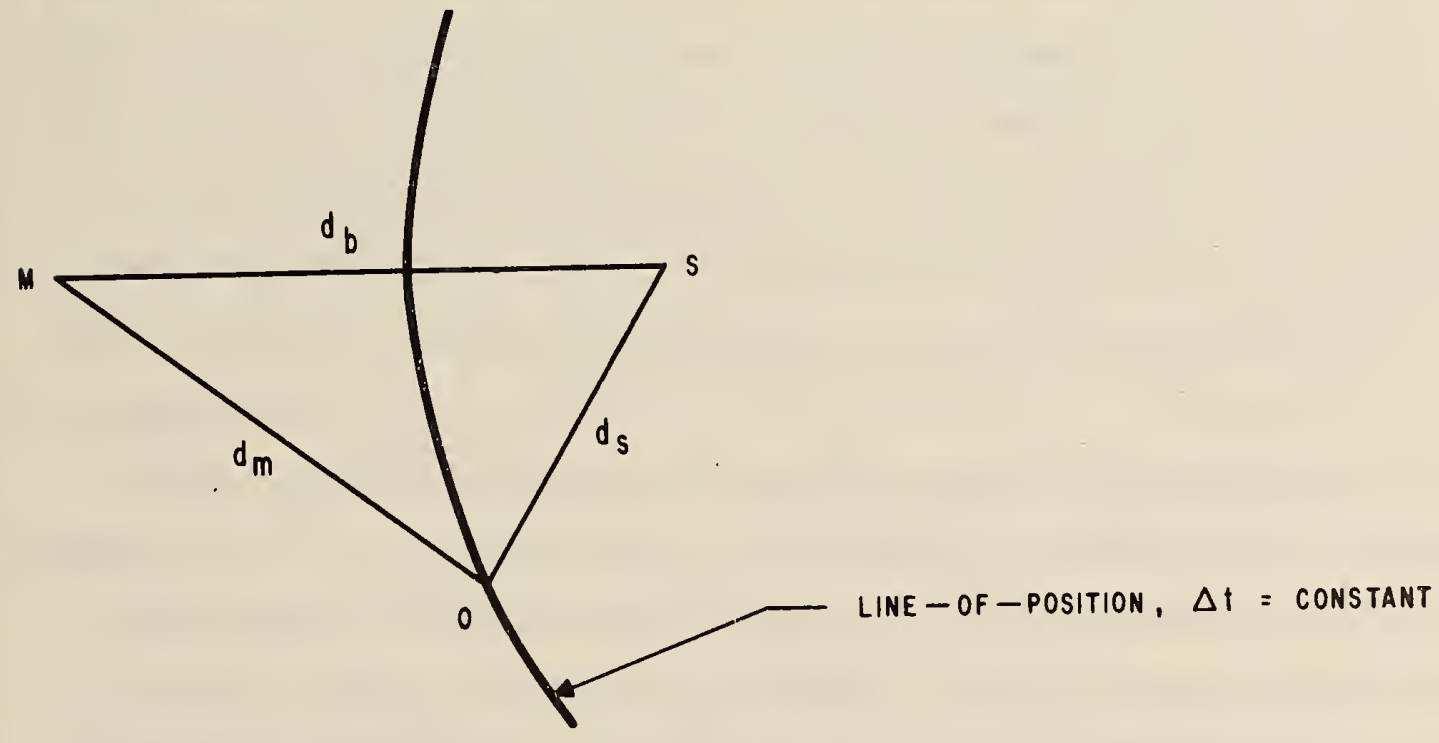

Figure 1. Radio navigator's hyperbolic line-of-position.

The principle of radio navigation can be described by the line-of position, figure 1. A master transmitter, M, and a slave "transponder", $S$, are separated by the length of baseline, $d_{b}$, which is ordinarily a constant. An observer, $O$, with a phase-difference indicator compares the phase of a signal transmitted to O directly (i.e., a trans mission with which the distance, $d_{m}$, is associated) with the signal 
received via the slave, $S$, (i.e., a transmission with which the distance, $d_{b}$, the slave, $S$, and the distance, $d_{s}$, are associated). If the phase-difference, $\Delta \phi$, cai be interpreted as a time, in microseconds, $\left(t=10^{6} \phi / \omega\right.$ at a transmission frequency, $\left.f=\omega / 2 \pi\right)$ then the time-difference, $\Delta t$, represents the phase measurement, or phase lock, of the automatic system.

$$
\Delta t=\frac{\eta_{1}}{c}\left[d_{b}+d_{s}-d_{m n}\right]+c_{s} \text {, }
$$

(where $\mathrm{C}_{\mathrm{S}}$ is the slave (S) coding delay which is a system constant, and $\eta_{1} / c$ is the reciprocal of the speed of light). The time difference, $\Delta t$, as a constant, together with a constant baseline, $d_{b}$, describes a hyperbolic locus of points known as a line-of-position, figure 1. Two such lines-of-position (which can be generated with the aid of one additional slave) determine a navigation " $\mathrm{fix}$ ". The transmission over the distances, $d_{b}, d_{s}, d_{m}$, is accomplished by use of $L F$ radio wave propagation. It is therefore evident that the system designer is interested in the LF field, $\mathbb{E}(\omega, d)$ volts/meter, and in particular the phase of the field, arg $E(\omega, d)$, at frequencies, $f=\omega / 2 \pi$ propagated over these distances. The existent Loran-C system employs the ground-wave mode [Johler, Kellax, and Walters, 1956], [Johler, Lilley, and Walters, 1959], [Johler, Lilley, and Walters, 1960] for transmissions over these distances to the exclusion of the ionosphere modes. Special instrumentation which utilizes pulse techniques and special radiated pulse signals, $E\left(t^{\prime}, d\right)$ volts/meter, which can be readily tagged at a point-in-time where $t^{\prime}$ is reckoned locally from the beginning of the pulse, $t^{\prime}=t-\eta \mathrm{d} / \mathrm{c}$, is required to achieve the ground-wave "phase lock" to the exclusion of the ionospheric modes. Thus it is necessary to consider the influence of the conduction and 
displacement currents in the ground, the curvature of the ground, and the proximity of the source (induction and electrostatic fields). It is, therefore, necessary to develop and apply a time correction, $t_{c}=t_{c}(d)$, for each distance transmission associated with the system. The time-difference equation is therefore corrected,

$$
\Delta t=\frac{\eta_{1}}{c}\left[d_{b}+d_{s}-d_{m}\right]+t_{c}\left(d_{b}\right)+t_{c}\left(d_{s}\right)-t_{c}\left(d_{m}\right)+c_{s},
$$

to describe the line-of-position with greater accuracy.

Recent proposals [Doherty, Hefley, and Linfield, 1960] have suggested the employment of the world-wide Loran-C system to move time around the world by means of such a "phase lock" to an accuracy of one microsecond or better. The ability of the system to synchronize to fractional microsecond precision, and the corresponding predictability of the ground-wave mode of propagation imply the feasibility of this application, hence the notation: Loran-C radio navigation timing system.

Since the Loran-C radio navigation system employs pulse techniques, a discussion of the analysis procedures requires special consideration of the pulse type transmission, $E\left(t^{\prime}, d\right)$ volts/meter. The general approach [Johler and Walters, 1959] was developed so that the $C W$ field, $E(\omega, d)$, could be related to the transient field, $E\left(t^{\prime} d\right)$, and the source, $F_{S}(t)$, by a direct evaluation of the Fourier transform integral,

$$
\begin{aligned}
E\left(t^{\prime}, d\right) & =\frac{1}{2 \pi} \int_{-\infty}^{\infty} \exp \left(i \omega t^{\prime}\right) E(\omega, d) \int_{0}^{\infty} \exp (-i \omega t) F_{s}(t) d t d \omega y \\
\text { or } E\left(t^{\prime}, d\right) & =\frac{1}{2 \pi} \int_{-\infty}^{\infty} \exp \left(i \omega t^{\prime}\right) E(\omega, d) F_{8}(\omega) d \omega .
\end{aligned}
$$


The complex source function, $F_{S}(t)$, introduced to simplify the operational techniques of analysis, also provided a description of an "ideal" amplitude envelope for the pulse, $\left|E\left(t^{\prime}, d\right)\right|$, which was propagated simultaneously with the pulse.

The transform of the propagation medium, $E(\omega, d)$ volts/meter, is a very complicated function which has been extensively described in the literature [Bremmer, 1949]. The transform is frequently represented geometric-optically at LF, such that the total field, $E(\omega, d)$, for the particular case of a vertically polarized dipole source can be written as the sum of time modes [Johler, 1961] of propagation, $\mathrm{j}=0,1,2,3 \cdots$, between the ionosphere and the earth,

$$
E(\omega, d)=\sum_{j=0}^{p} E_{j}(\omega, d) \text {, }
$$

in which the zero order $(j=0)$ time mode, $E_{0}(\omega, d)$, is the ground wave. Each time mode of propagation, $j=1,2,3 \cdots$ or $j \neq 0$, is,

$$
E_{j}(\omega, d)=i \omega d D_{j}^{-1} C \exp \left(i \omega t^{i}{ }_{j}\right) G_{j}^{t} G^{r}{ }_{j} \alpha_{j} F_{j} C_{j} \text {, }
$$

where,

$$
C=I_{0} l b^{2} / 4 \pi k d^{3}=\left(10^{-7}\right) / d,\left(I_{0} l=1\right)
$$

and the local time for the ground wave, ' $t$ ' 0 , is,

$$
\begin{aligned}
& \mathrm{t}^{\mathrm{I}}=\mathrm{t}-\mathrm{b}, \\
& \mathrm{b}=\eta_{1} \mathrm{~d} / \mathrm{c},
\end{aligned}
$$


where [Johler, Kellar, and Walters, 1956]

$$
E_{o}(\omega, d)=\left\{E_{o}(\omega, d)\right] \exp \left[-i\left(\omega b+\phi_{c}\right)\right] \text {, }
$$

where $c$ is the speed of light, $c \sim 3\left(10^{8}\right)$ meters/second, and $\eta_{1}$ is the index of refraction of air, $\eta_{1} \sim 1.000338$ typically, and similariy, the local sky-wave time, or sky-wave delay, $t^{\prime}{ }_{j}(j=1,2,3 \cdots)$ is,

$$
\begin{aligned}
& \mathrm{t}^{\mathrm{t}}{ }_{\mathrm{j}}=\mathrm{t}-\mathrm{b}_{\mathrm{j}}, \\
& \mathrm{b}_{\mathrm{j}}=\eta_{1} \mathrm{D}_{j} / \mathrm{c},(j=1,2,3 \cdots)
\end{aligned}
$$

The quantity, $b_{j}-b$, is frequently called the relative sky-wave delay, figure 2 (relative to the ground wave). The physical length of the ray, $D_{j}$, can be evaluated geometrically for a reflection at an altitude, $h$, above the surface of the earth of radius, a,

$$
D_{j}=2 j\left[(a+h) \cos \phi_{i, j}-a \cos T_{j}\right]
$$

where $\phi_{i}$ is the angle of incidence of the "ray" on the ionosphere and $\tau_{j}$ is the corresponding angle of incidence on the Earth (the subscript " $j$ " reminds the reader that the equation refers to the particular time mode under consideration). The angles, $\phi_{i}$ and $\tau_{j}$, are evaluated quite simply from the geometry if

$$
\begin{aligned}
& \sin \phi_{i, j}=\Delta_{j}^{-1} a \sin \frac{\theta}{2 j}, \\
& \cos \phi_{i, j}=\Delta_{j}^{-1}[a(1-\cos \theta / 2 j)+h],
\end{aligned}
$$




$$
\begin{aligned}
& \sin \tau_{j}=\Delta_{j}^{-1}(a+h) \sin \theta / 2 j, \\
& \cos \tau_{j}=\Delta_{j}^{-1}[a(\cos \theta / 2 j-1)+h \cos \theta / 2 j), \\
& \Delta_{j}=\left[2 a(a+h)(1-\cos \theta / 2 j)+h^{2}\right]^{\frac{1}{2}},
\end{aligned}
$$

where $\theta$ is the angle at the center of the earth subtended by the distance, $d$, along the surface of a spherical earth, or, simply, $d=a \theta$. The factors, $G^{t}$ and $G^{r}{ }_{j}$, refer to the transmitter and receiver vertical antenna patterns respectively, and again the subscript, " $j "$, is employed to designate the particular time mode under consideration. The vertically polarized Hertzian dipoles reduce to $G^{t}{ }_{j}=G_{j}^{r}=\sin \tau_{j}$. Of course other antenna patterns can be introduced by these factors.

The factor, $F_{j}$ [Johler, 196Ib], [Wait, 1958], describes the antenna pattern corrections of the transmitter and receiver antennas at grazing angles of incidence on the earth and the factor, $C_{j}$, describes the effective reflection coefficient for multiple hops or a single hop between the ionosphere and the Earth [Johler, 1961b],

$$
\begin{aligned}
& C_{j}=\frac{1}{j ! R_{e}} \frac{d^{j}}{d x^{j}}\left[\frac{1+A_{1} x}{1-A_{2} x-A_{3} x^{2}}\right]_{x=0} \\
& A_{1}=-R_{m} T_{m m} \\
& A_{2}=R_{e} T_{e e}+R_{m} T_{m m} \\
& A_{3}=R_{e} R_{m}\left[-T_{e e} T_{m m}+T_{e m} T_{m e}\right],
\end{aligned}
$$

where $R_{e}$ and $R_{m}$ are the ground-reflection coefficients for vertical 
and horizontal polarization and $\mathrm{T}_{\text {ee, }} \mathrm{T}_{\mathrm{erm}} \mathrm{T}_{\mathrm{me}}$, and $\mathrm{T}_{\mathrm{mm}}$, - are the ionosphere reflection coefficients [Johler and Walters, 1960] [Johler, 1961c] [ Johler and Harper, 1962].

Since plane-reflection coefficients, $T$, are employed in this type of analysis, the convergence-divergence factor, $\alpha_{j}$, is necessary to convert plane-reflection coefficients to sphericai-reflection coefficients, or from the view point of ray theory it is necessary to take account of ray focusing by the ionosphere and a corresponding defocusing of rays by the Earth.

As a consequence of the time modes,

$E\left(t^{p}, c_{j}\right)=\sum_{j=0}^{P} E_{j}\left(t^{q}, d\right)=\sum_{j=0}^{p} \frac{y}{2 \pi} \int_{-\infty}^{\infty} \exp \left(i \omega t_{j}^{q}\right) E_{j}(\omega, d) E_{g}(\omega) d \omega$.

This merely represents the sum of separate Fourier integrals for each time mode, separated in tirne by the sky-wave time-mode

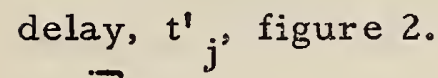

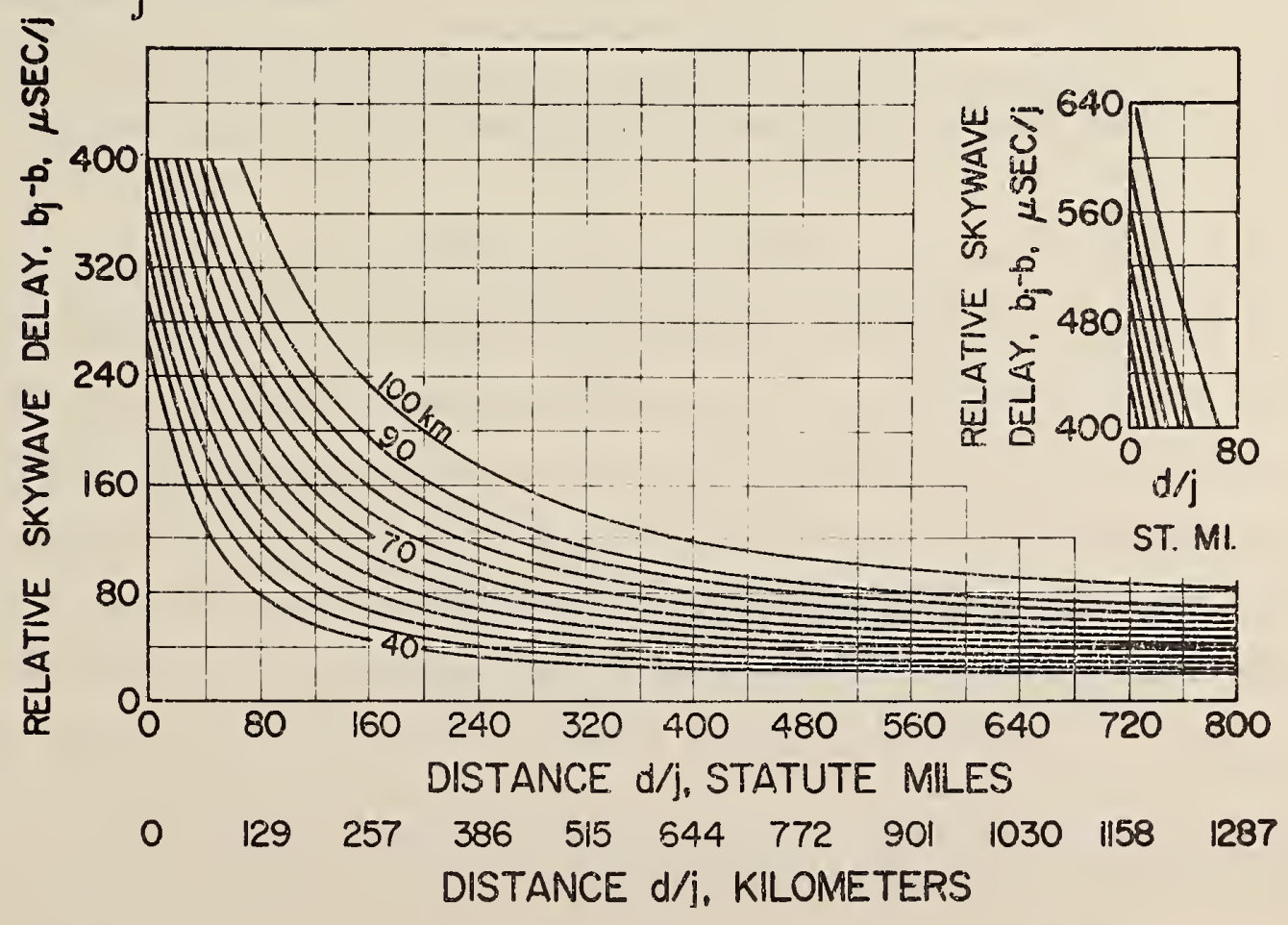

Figure 2. Relative sky-wave delay for various model ionosphere boundary ernplacement altitudes, $h$. 

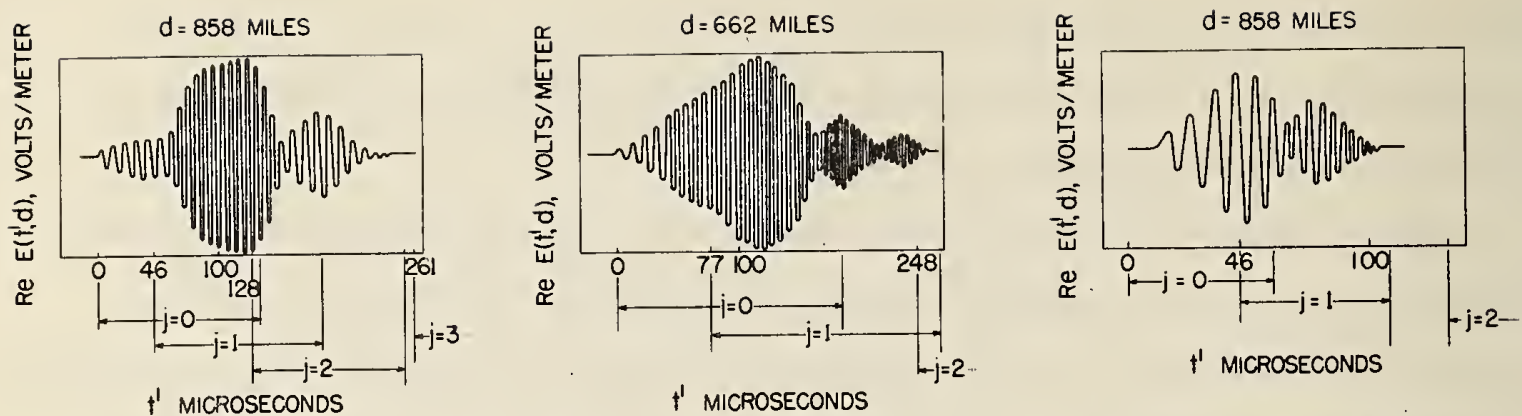

'MICROSECONDS
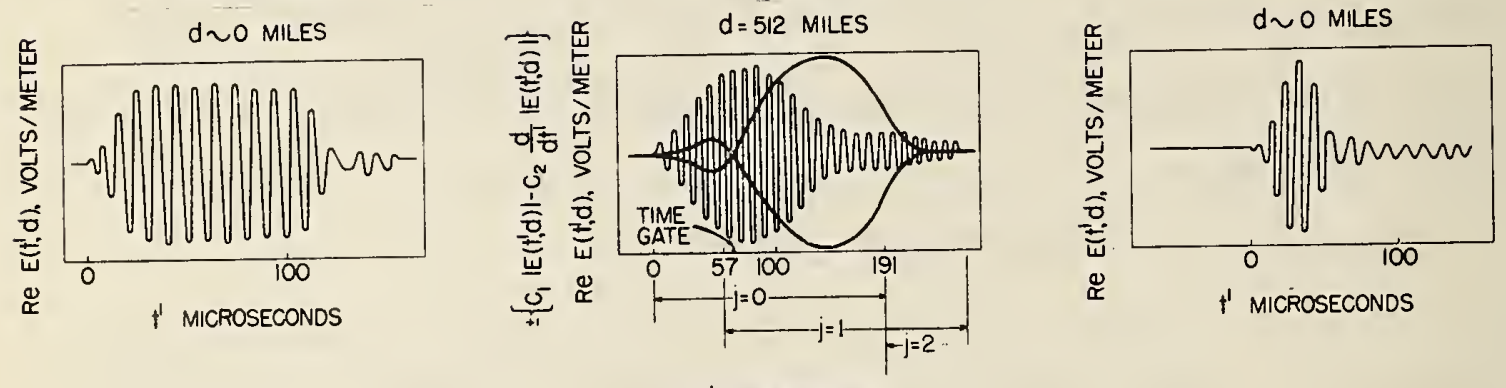

(a) NIGHTTIME

(b) NIGHTTIME

(c) DAYTIME

Figure 3. Observations of time modes with the aid of pulses of various lengths illustrating the separation of time modes and the measurement of a point-in-time on the leading edge of the pulse with the "amplitude envelope minus the derivative of the amplitude envelope" method, (August $1953, \mathrm{f}=100 \mathrm{kc} / \mathrm{s}$ ).

The sum of the time modes is illustrated for various (Cytac) Loran-C, Radio Navigation System pulses, figure 3. The undisturbed form of the radiated pulse is shown by oscillograms which were made at short distances. The action of the propagation medium is evidenced by the complicated, multiple, superposed pulses observed at great distances. Thus the oscillogram or amplitude-time function, Re $E\left(t^{\prime}, d\right)$, observed at great distance, comprises the superposed

From the author's personal notes on the 1953-1954 preliminary testing of the Loran-C (Cytac) system. 
time modes, $E_{j}\left(t^{\prime}, d\right), j=0,1,2,3 \cdots$, a pparently added together according to the complex field specification, $E_{j}$, of each and separated in time by the sky-wave delay, $t^{\prime}{ }_{j}$, of each time mode, $j$. The approximate area in the amplitude-time plane occupied by each mode of propagation is shown, figure 3. Areas of overlap in which both constructive and destructive interference between cycles of the multiple pulses produces notches and enhancements in the composite pulse can be observed.

The instrumentation which has been developed for the Cytac and Loran-C systems is quite capable of elegantly tagging cycles and minute fractions of a cycle on each of the multiple pulses. The envelope detector, in effect, forms the difference between the amplitude envelope, $\left|E\left(t^{\prime}, d\right)\right|$, and its derivate, $\frac{d}{d t^{\prime}}\left|E\left(t^{\prime}, d\right)\right|$, and an elaborate servomechanism seeks out a null point or zero crossing time for the time-function, thus determining a time-root, $I_{c}$, of the differential equation, illustrated, figure 3 ,

$$
F\left(t^{\prime}, d\right)=c_{1}\left|E\left(t^{\prime}, d\right)\right|-c_{2} \frac{d}{d t^{1}}\left|E\left(t^{\prime}, d\right)\right|=0
$$

where $c_{1}$ and $c_{2}$ are constants which move the point-in-time which is to be tagged on the oscillogram and which can be set by the operator to pick out a particular point on the pulse. Both amplitude and time (phase) can be measured at such a point. Additional techniques to detect cycles and minute fractions of a cycle under the envelope on the leading edge of a pulse have also been developed [Frantz, Dean, and Frank, 1957 J and the appropriate time-correction, ' $c$ ' of the continuous wave, $E(\omega, d)$, is appropriate in this case. 
The earliest time-root, $T_{c}=T_{c}(d)$, of this equation, $F\left(t^{\prime} d\right)=0$, constitutes the dispersion correction for the navigator's line-ofposition $(1,2)$ for propagation via ionospheric modes, or

$$
\begin{aligned}
\Delta t= & \frac{\eta_{1}}{c}\left[D_{j}\left(d_{b}\right)+D_{j}\left(d_{s}\right)-D_{j}\left(d_{m}\right)\right]+T_{c}\left(d_{b}\right)+T_{c}\left(d_{s}\right) \\
& -T_{c}\left(d_{m}\right)+C_{s} .
\end{aligned}
$$

The ground-wave mode is characterized by negligible dispersion for the type of pulses employed, $T_{c}(d)=t_{c}(d)+c$, where $c$ is a constant which becomes part of the coding delay, $\mathrm{C}_{s}$, and of course, the ray length, $D_{j}(d)=d$, by definition.

The theory which can predict the behavior of pulses is, therefore, an important adjunct to a system-prediction analysis. The radiated field from a step or impulse-current dipole source has been the subject of considerable discussion among theoreticians [Johler and Walters, 1959] since such functions are quite simple to evaluate. Thus the field of a step-function dipole current source can be written

$$
\left.E\left(t^{q}, d\right)=\frac{1}{\pi} \int_{0}^{\infty} \mid E(\omega, d)\right]\left\{\frac{1}{\omega} \sin \left[\omega t^{q}-\phi_{c}^{p}\right]\right\} d \omega,
$$

and the particular case of the ground-wave mode, writing $\phi_{c}^{l}=\phi_{c}-\frac{\pi}{2}$ $E_{O}(\omega, d)=\left|E_{O}(\omega, d)\right| \exp \left[-i \phi_{C}\right]$, is illustrated, figure 4, $(d=1000$ statute miles). The impulse-source-current dipole (vertical polarization) reduces to the following simple formula,

$$
E\left(t^{3}, d\right)=\frac{1}{\pi} \int_{0}^{\infty}|E(\omega, d)|\left\{\cos \left[\omega t^{2}-\phi_{C}^{3}\right]\right\} d \omega .
$$


The results of a quadrature evaluation [Johler and Walters, 1959] [Johler and Lilley, 1961] of this integral are also illustrated, figure 4 , for the ground-wave mode of propagation.

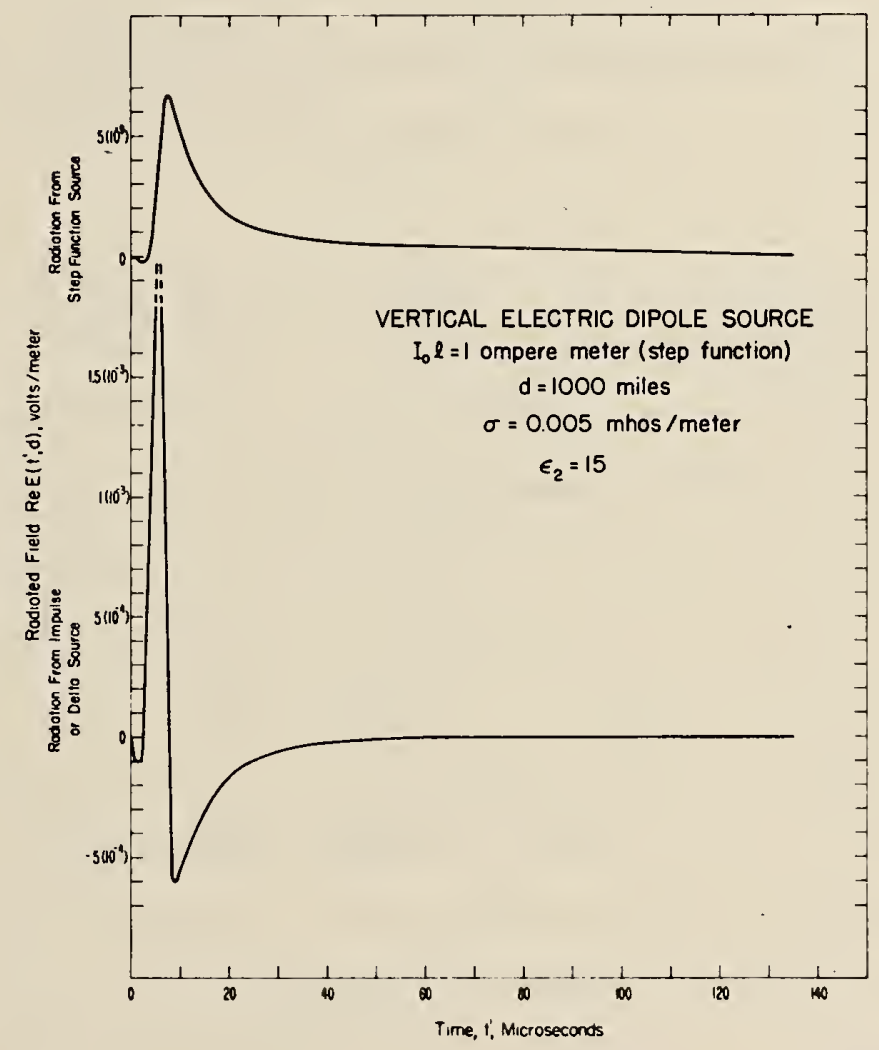

Figure 4. The step and impulse-source current radiation at a great distance from the source.

These pulses give physical insight into the propagation mechanism, but are of little assistance to the system designer. More sophisticated pulses must be developed mathematically and the transfer function of the system equipment must be considered.

The finite bandwidth of a receiver or filter can be introduced, equations ( 3 and 4 ), by a mutilation of the Fourier transform with one or more frequency-selective networks. The intervals can then be evaluated by quadrature methods [Johler and Walters, 1959]. In 
principle, this simplifies the numerical problem of integration, since the range of integration necessary to achieve convergence of the integral, already limited by the propagation medium, is further limited by the operation of the receiver transfer function or filter on the pulse image. The generalized Fourier transform, for some complicated source function, can then be represented as follows:

$f(\omega, d)=E(\omega, d)\left[f_{s_{0} 1}(\omega)+f_{s_{9}, 2}(\omega)+\cdots\right]\left[f_{r_{0} 1}(\omega) f_{r_{8} 2}(\omega) \cdots\right] \cdot$

$f_{s, 1}(\omega) f_{s, 2}(\omega) \cdots$ are source transforms which have been superposed to determine some complicated waveform. $f_{r, 1}(\omega), f_{r, 2}(\omega) \cdots$ are transfer functions of the frequency-selective network which have been introduced to mutilate the transform or, in effect, restrict the frequency spectrum of the pulse.

The damped sinusoid, $F_{s}(t)=\exp (-v t), v=c_{1}+i \omega_{c}$, where $c_{1}$ is the damping and $f_{c}=\omega_{c} / 2 \pi$ is the characteristic frequency, is a more sophisticated pulse [Johler and Walters, 1959] which has found useful application to system studies. It is necessary, however, to take into consideration the receiver or filter. Perhaps the simplest case is the following series network:

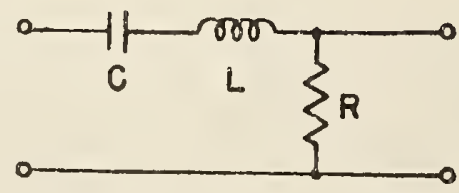

The frequency response, $f_{r}(s), s=i \omega$, of this network can be written:

$$
f_{r}(s)=\frac{\left(\frac{R}{L}\right) s}{s^{2}+\left(\frac{R}{L}\right) s+\frac{1}{C L}}
$$


The damped cosine source model [Johler and Walters, 1959] $\exp (-\nu t), \nu=c_{1}+i \omega_{c}$, can be assumed in such a way that the transform, $f(s)$, is as follows:

$$
f(s)=\frac{(\alpha+\beta) s}{(s+v)(s+\alpha)(s+\beta)}
$$

or,

$$
f(s)=\frac{\frac{\nu \beta}{\alpha \beta}-\frac{\nu \alpha}{\alpha \beta}}{\Delta(s+v)}+\frac{\frac{\nu \alpha}{\alpha \beta}-1}{\Delta(s+\alpha)}+\frac{1-\frac{\nu \beta}{\alpha \beta}}{\Delta(s+\beta)} .
$$

where $\Delta$ is described by the determinant,

$$
\Delta=\left|\begin{array}{ccc}
1 & 1 & 1 \\
1 & \frac{v+\beta}{\alpha+\beta} & \frac{v+\alpha}{\alpha+\beta} \\
1 & \frac{v \beta}{\alpha \beta} & \frac{v \alpha}{\alpha \beta}
\end{array}\right|
$$

and,

$$
\begin{aligned}
& \alpha=\frac{R}{2 L}+\frac{1}{2} \sqrt{\left(\frac{R}{L}\right)^{2}-\frac{4}{C L}} \\
& \beta=\frac{R}{2 L}-\frac{1}{2} \sqrt{\left(\frac{R}{L}\right)^{2}-\frac{4}{C L}}
\end{aligned}
$$

For the special case, 


$$
\begin{aligned}
& \left(\frac{R}{L}\right)^{2}<\frac{4}{C L} \\
& \alpha=\frac{R}{2 L}+\frac{1}{2}+\sqrt{\left(\frac{R}{L}\right)^{2}-\frac{4}{C L}} \\
& \beta=\alpha
\end{aligned}
$$

i. e., $\alpha$ and $\beta$ are conjugate frequencies. This special case characterizes a "ringing" circuit as a result of the introduction of the oscillatory terms with frequencies, Im $\alpha$ and $\operatorname{Im} \beta$, which correspond to the resonant frequency of the circuit. Exponential damping, $\exp (-R / 2 L)$, is also introduced by the circuit. It can, therefore, be concluded that the effect of a simple series-resonant circuit is the same as the sum of three oscillatory waves as follows:

$$
E\left(t^{p}, d\right)=A E_{\nu}\left(t^{p}, d\right)+B E_{\alpha}\left(t^{0}, d\right)+C E_{\beta}\left(t^{p}, d\right),
$$

where each wave is calculated by published [Johler and Walters, 1959] quadrature methods at the following complex frequencies:

$$
\begin{aligned}
& \nu=c_{1}+i \omega_{c} \\
& \alpha=c_{2}+i \omega_{r} \\
& \beta=c_{3}-i \omega_{r}
\end{aligned}
$$

where, 
$-15-$

$$
\begin{aligned}
& c_{2}=c_{3}=\frac{R}{2 L} \quad\left(\frac{R}{L}\right)^{2}<\frac{4}{C L} \\
& \left.c_{2}=\alpha\right\}\left(\frac{R}{L}\right)^{2}>\frac{4}{C L} \\
& \left.c_{3}=\beta\right\} \\
& \omega_{r}=\frac{1}{2} \sqrt{\left(\frac{R}{L}\right)^{2}-\frac{4}{C L} \mid}\left(\frac{R}{L}\right)^{2}<\frac{4}{C L} \\
& \omega_{r}=0 \\
& \left(\frac{R}{L}\right)^{2}>\frac{4}{C L}
\end{aligned}
$$

The constants $A, B$, and $C$ are defined as follows:

$$
\begin{aligned}
& A=\Delta^{-1}\left[\frac{\nu \beta}{\alpha \beta}-\frac{\nu \alpha}{\alpha \beta}\right] \\
& B=\Delta^{-1}\left[\frac{\nu \alpha}{\alpha \beta}-1\right] \\
& C=\Delta^{-1}\left[1-\frac{\nu \beta}{\alpha \beta}\right]
\end{aligned}
$$




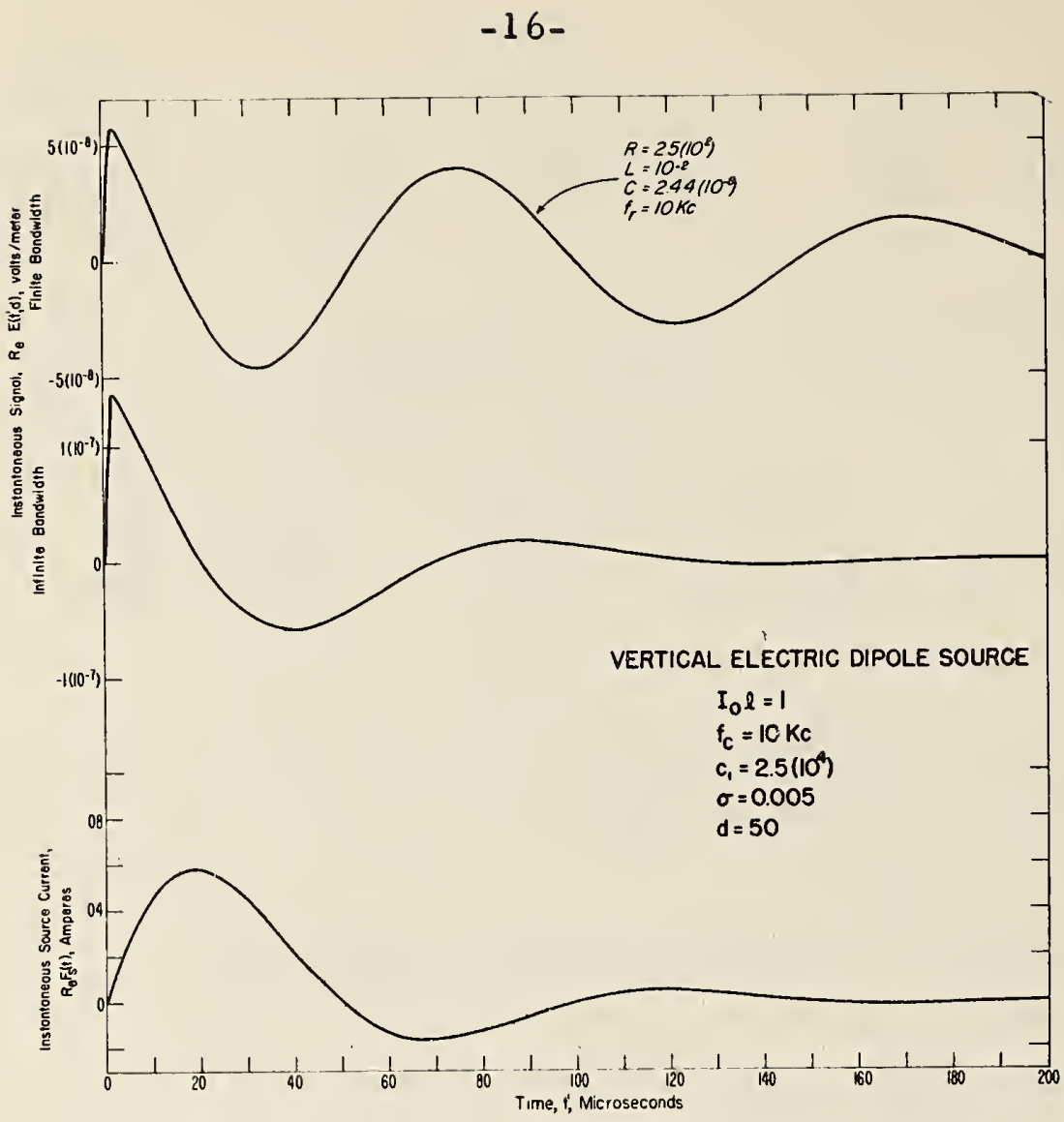

Figure 5. Comparison of the calculation of the pulse observed through an infinite bandwidth receiver with the calculation of the same pulse observed through a finite bandwidth receiver, illustrating the effect of "harrow band" as compared with "broad band" receiver.

The more complicated filters, $f_{\mathbf{r}^{\circ}}(\omega)$, are introduced as a mutilation of the Fourier transform, $f(\omega, d)$, simply by complex multiplication,

$$
f(\omega, d)=E(\omega, d) f_{s}(\omega) f_{r}(\omega)
$$

The filter transfer function, $f_{\mathbf{r}}(\omega)$, can be measured experimentally, preferably at precalculated Gaussian frequencies, $\omega_{m}$ [Johler and 
Walters, 1959], suitable for quadrature methods provided that both amplitude and phase are measured for each frequency. The Fourier transform (37) can then be formed and the Fourier integral $(3,4)$ can then be evaluated. The results of such a calculation are illustrated, figures 5 and 6, for two damped sinusoids by a comparison of the pulse in an "infinite" bandwidth receiver with a receiver of restricted bandwidth and, as might be expected, the ringing of the filter as a result of the oscillatory terms (33) is evident.

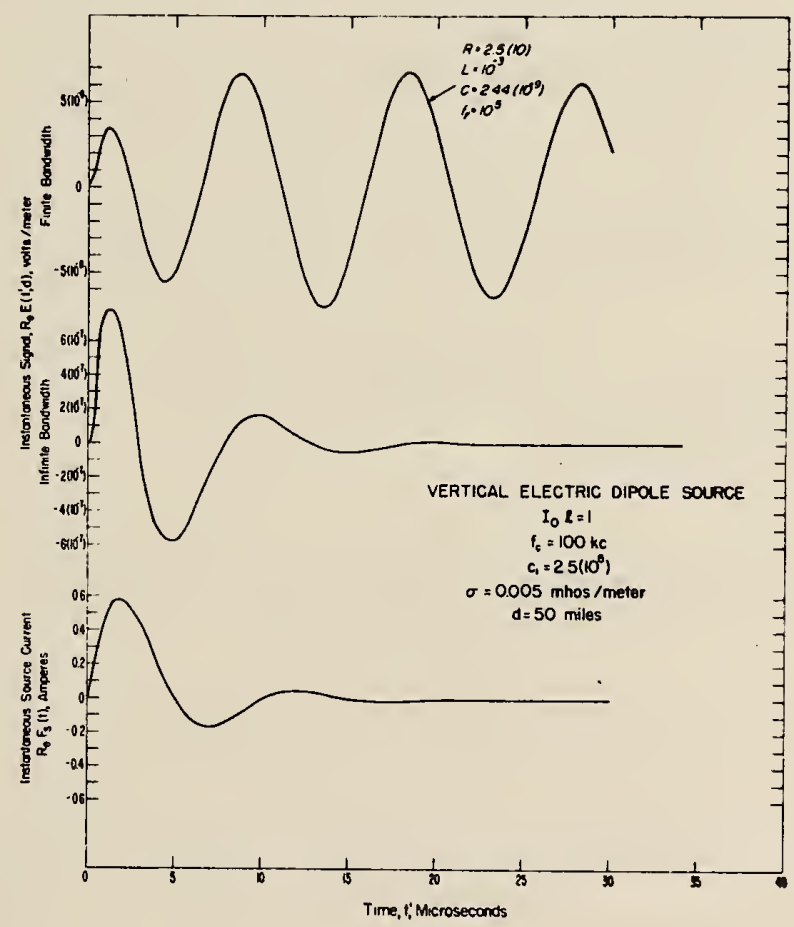

Figure 6. Comparison of the calculation of the pulse observed through an infinite-bandwidth receiver with the calculation of the same pulse observed through a finite-bandwidth receiver.

A useful model for the type of pulse normally employed in radio navigation systems can be readily synthesized by superposition of damped sinusoids. For example, the "classical" sine-squared pulse can be evaluated by redefining the source function, 
$\operatorname{Re} F_{s}(t)=\exp \left(-c_{1} t\right) \sin ^{2} \omega_{p} t \sin \omega_{c} t$

or,

$$
\begin{aligned}
& \operatorname{Re} F_{s}(t)=\frac{1}{2} \exp \left(-c_{1} t\right) \sin \omega_{c} t-\frac{1}{4} \exp \left(-c_{1} t\right) \sin \left(\omega_{c}+2 \omega_{p}\right) t \\
& -\frac{1}{4} \exp \left(-c_{1} t\right) \sin \left(\omega_{c}-2 \omega_{p}\right) t,
\end{aligned}
$$

or, the complex source function,

$$
F_{s}(t)=\frac{i}{2} \exp (-v t)-\frac{i}{4} \exp \left(-v_{1} t\right)-\frac{i}{4} \exp \left(-v_{2} t\right),
$$

can be employed for envelope synthesis, where,

$$
\begin{aligned}
& v=c_{1}+i \omega_{c} \text { (as before) } \\
& v_{1}=c_{1}+i\left(\omega_{c}+2 \omega_{p}\right) \\
& v_{2}=c_{1}+i\left(\omega_{c}-2 \omega_{p}\right) .
\end{aligned}
$$

Typically, the radio navigation type pulse has a value for $c_{1}$ of the order of $\omega_{\mathrm{p}}$. It is quite obvious, however, that the transient field, $E\left(t^{\prime}, d\right)$, for the damped sine-squared source-current pulse is merely the sum of three waves calculated as previously described damped sinusoids,

$$
E\left(t^{t} d\right)=\frac{i}{2} E_{\nu}\left(t^{t}, d\right)+\frac{-i}{4} E_{v_{1}}\left(t^{t}, d\right)+\frac{-i}{4} E_{v_{2}}\left(t^{t}, d\right)
$$



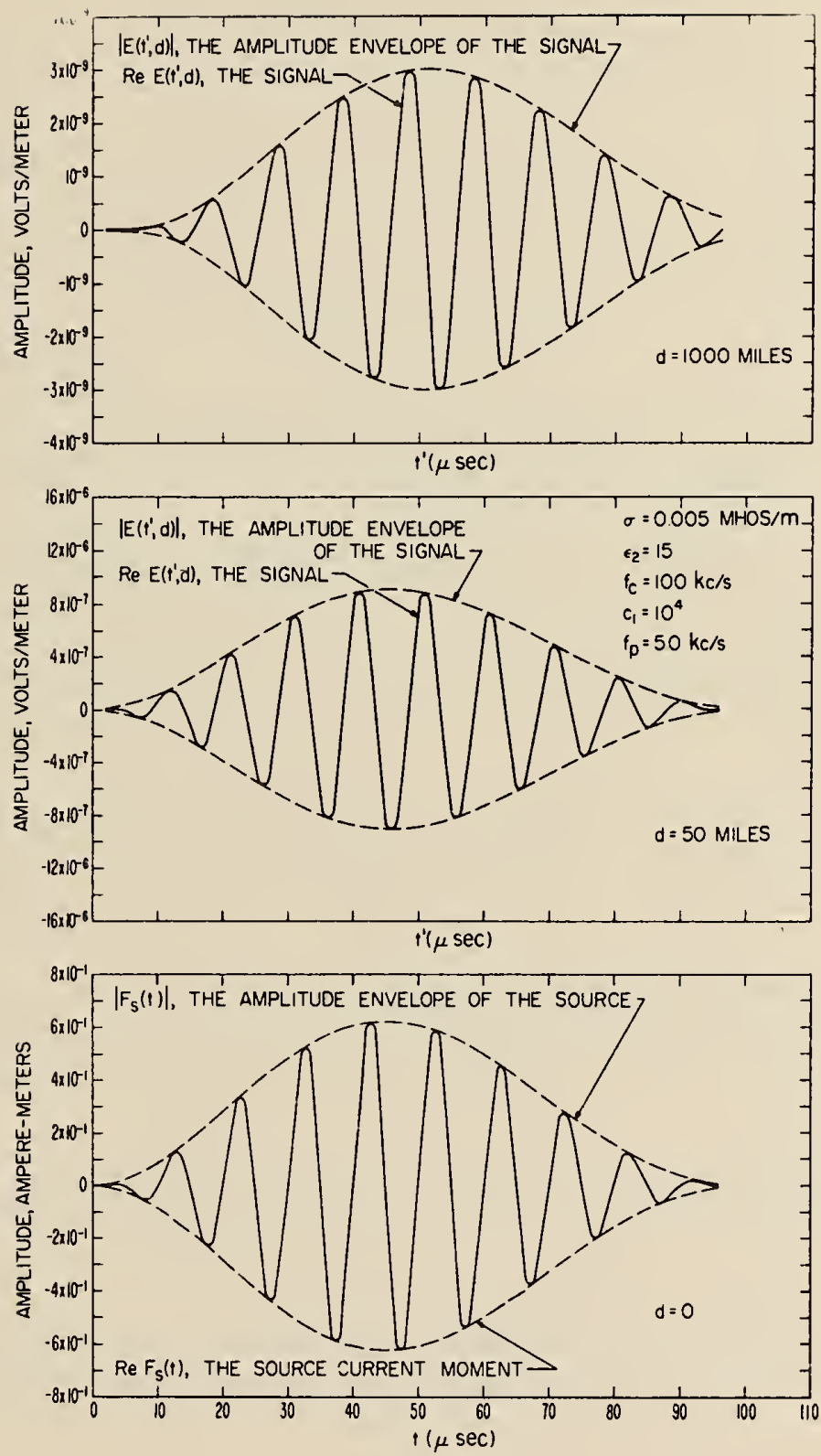

Figure 7. The damped sine-squared pulse, illustrating a radio navigation system type of pulse with corresponding amplitude envelope. 

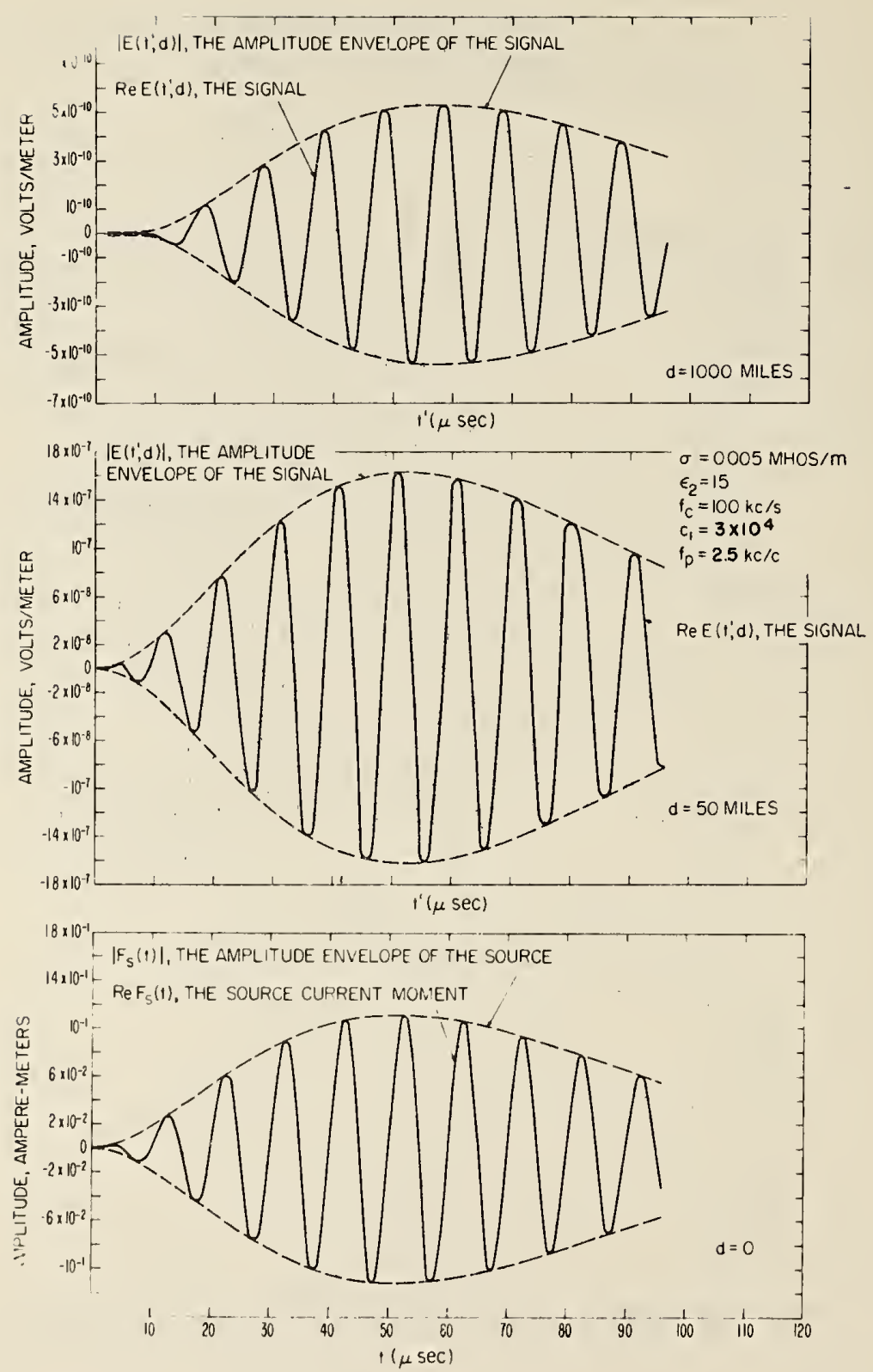

Figure 8. The damped sine-squared pulse, illustrating a radio navigation system type of pulse with corresponding amplitude envelope. 
The results of a radio navigation system pulse synthesis are illustrated for propagation of a damped sinusoidal sine-squared source current to a distance of 50 to 1000 miles, figs. 7, 8. Both the "oscillogram" or observed waveform, $R e E\left(t^{\prime}, d\right)$, and the synthetic amplitude envelope, $\left|E\left(t^{\prime}, d\right)\right|$, are illustrated.

\section{REFERENCES}

Bremmer, H., Terrestrial radio waves - theory of propagation, (Elsevier Publ. Co., New York, N. Y., 1949).

Doherty, R. H., G. Hefley, and R. F. Linfield, Timing potentials of Loran-C. Proceedings of 14 th annual frequency control symposium, Ft. Monmouth, N. J., sponsored by the U. S. Army Research and Development Laboratory (June 1960) (proceedings to be published).

Frantz, W. P., W. N. Dean, and R. C. Frank, A precision multipurpose radio navigation system, 1957 I. R. E. Convention Record, Pt. 8, 79-120 (Maxch 18-24, 1957).

Johler, J. R., On L.F ionospheric phenomena in radio navigation systems, proceedings of AGARD meeting, Istanbul (October 1960), (to be published by Pergamon Press, 1961a).

Johler, J. R., On the analysis of LF ionospheric propagation, J. Research NBS 65D (Radio Prop.) No. 5, p. 507 (Sept. .-Oct. 1961b)

Johler, J. R، , Magneto-ionic propagation phenomena in lowand very low-radiofrequency waves reflected by the ionosphere, J. Research NBS 65D, No. 1, 53-65 (January-February 1961c).

Johler, J. R., and J. D. Harper, Jx., Reflection and transmission of radio wave at a continuously stratified plasma with a high magnetic induction, J. Research NBS 66D (Radio Prop.) No. 1 (January-February 1962) (in publication at time of printing). 
Johler, J. R., W. J. Kellar, and L. C. Walters, Phase of the low radiofrequency ground wave, NBS Circular 573, U. S. Government Printing Office, Washington 25, D. C. (June 26, 1956).

Johler, J. R., and C. M. Lilley, Ground conductivity determinations at low-radiofrequencies by an analysis of spheric signatures of thunderstorms, J. Geophy. Research 66, No. 10 (October 1961) (in publication at time of printing).

Johler, J. R., C. M. Lilley, and L. C. Walters, Low-and very low-radiofrequency tables of ground wave parameters for the spherical earth theory: The roots of Riccati's differential equation, NBS Technical Note No. 7, PB 151366, U. S. Dept. of Commerce, Office of Technical Services, Washington 25, D. C. (February 1, 1959).

Johler, J. R., C. M. Lilley, and L. C. Walters, Amplitude and phase of the low - and very low-radiofrequency ground wave, NBS Technical Note No. 60, PB 161561, U. S. Dept, of Commerce, Office of Technical Services, Washington 25, D. C. (June 1, 1960).

Johler, J. R., and L. C. Walters, Propagation of a groundwave pulse around a finitely-conducting spherical earth from a damped sinusoidal source current, I. R. E. AP-7, No. 1, 1-10 (January 1959).

Johler, J. R., and L. C. Walters, On the theory of reflection of low - and very low-radiofrequency waves from the ionosphere. J. Research NBS 64D, No. 3 269-285 (May-June 1960).

Ross, J. M., Propagation field test, Appendix D (uncl.) Navigation, guidance, and control system for drone aircraft, 6th quarterly progress report to U. S. Army Signal Research and Development Laboratory, Ft. Monmouth, N. J., (SeptemberNovember 1959), Contract No. DA 36-039 SC-78020, Motorola, Inc., Scotsdale, Arizona. 
Schneider, A. B., Phase variations with range of the groundwave signal from CW transmitters in the $70-130 \mathrm{kc} / \mathrm{s}$ band, J. British Inst. Radio Engineers 12, No. 3, 181-184 (March 1955).

Wait, J. R., A. M. Conda, Pattern of an antenna on a curved long surface, I. R.E. Trans AP-6, No. 4, 348-359 (October 1958). 



\section{THE NATIONAL BUREAU OF STANDARDS}

The scope of activities of the National Bureau of Standards at its major laboratories in Washington, D.C., and Boulder, Colorado, is suggested in the following listing of the divisions and sections engaged in technical work. In general, each section carries out specialized research, development, and engineering in the field indicated by its title. A brief description of the activities, and of the resultant publications, appears on the inside of the front cover.

\section{WASIIINGTON, D.C.}

Electricity. Resistance and Reactance. Electrochemistry. Electrical Instruments. Magnetic Measurements. Dielectrics.

Metrology. Photometry and Colorimetry. Refractometry. Photographic Research. Length. Engineering Metrology. Mass and Scale. Volumetry and Densimetry.

lleat. Temperature Physics. Heat Nieasurements. Cryogenic Physics. Equation of State. Statistical Physics. Radiation Physics. X-ray. Radioactivity. Radiation Theory. High Energy Radiation. Radiological Equipment. Nucleonic lnstrumentation. Neutron Physics.

Analytical and Inorganic Chemistry. Pure Substances. Spectrochemistry. Solution Chemistry. Standard Reference Materials. Applied Analytical Research.

Mechanics. Sound. Pressure and Vacuum. Fluid Mechanics. Engineering Mechanics. Rheology. Combustion Controls.

Organic and Fibrous Materials. Rubber. Textiles. Paper. Leather. Testing and Specifications. Polymer Structure. Plastics. Dental Research.

Metallurgy. Thermal Metallurgy. Chemical Metallurgy. Mechanical Metallurgy. Corrosion. Metal Physics. Electrolysis and Metal Deposition.

Mineral Products. Engineering Ceramics. Glass. Refractories. Enameled Metals. Crystal Growth. Physical Properties. Constitution and Microstructure.

Building Research. Structural Engineering. Fire Research. Mechanical Systems. Organic Building Materials. Codes and Safety Standards. Heat Transfer. Inorganic Building Materials.

Applied Mathematics. Numerical Analysis. Computation. Statistical Engineering. Mathematical Physics. Operations Research.

Data Processing Systems. Components and Techniques. Digital Circuitry. Digital Systems. Analog Systems. Applications Engineering.

Atomic Physics. Spectroscopy. Infrared Spectroscopy. Solid State Physics. Electron Physics. Atomic Physics. Instrumentation. Engineering Electronics. Electron Devices. Electronic Instrumentation. Mechanical Instruments. Basic Instrumentation.

Physical Chemistry. Thermochemistry. Surface Chemistry. Organic Cinemistry. Molecular Spectroscopy. Molecular Kinetics. Mass Spectrometry.

Office of Weights and Measures.

\section{BOULDER, COLO.}

Cryogenic Engineering. Cryogenic Equipment. Cryogenic Processes. Properties of Materials. Cryogenic Technical Services.

Ionosphere Research and Propagation. Low Frequency and Very Low Frequency Research. Ionosphere Research. Prediction Services. Sun-Earth Relationships. Field Engineering. Radio Warning Services.

Radio Propagation Engineering. Data Reduction lnstrumentation. Radio Noise. Tropospheric Measurements. Tropospheric Analysis. Propagation-Terrain Effects. Radio-Neteorology. Lower Atmosphere Physics.

Radio Standards. High Frequency Electrical Standards. Radio Broadcast Service. Radio and Microwave Materials. Atomic Frequency and Time lnterval Standards. Electronic Calibration Center. Millimeter-Wave Research. Microwave Circuit Standards.

Radio Systems. High Frequency and Very High Frequency Research. Modulation Research. Antenna Research. Navigation Systems.

Upper Atmosphere and Space Physics. Upper Atmosphere and Plasma Physics. lonosphere and Exosphere Scatter. Airglow and Aurora. lonospheric Radio Astronomy. 


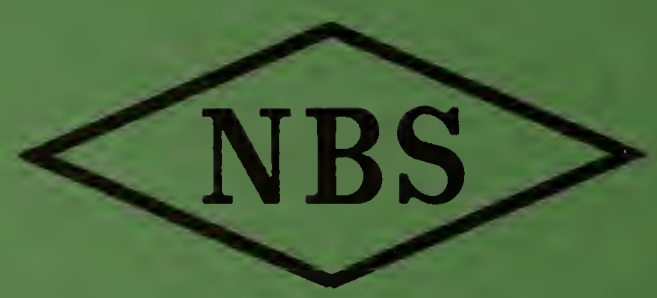

